\title{
Ethnofarming Practices among Subanen and Mansaka
}

\author{
Anabelie V. Valdez and Carmelita G. Hansel
}

\begin{abstract}
Ethnofarming practices of some select indigenous groups in Mindanao, was conducted from July 2011 to February 2012. Inquiry on the demographic characteristics and life ways of the study's population yielded the following information: The study found that the Subanen and the Mansaka farmers have a low level of educational attainment. Most were aged 65 and above and were not able to go to school. Magical, traditional, and factual procedures and techniques figured prominently among the crop farming practices of the Subanen and Mansaka farmers. Factual practices include the following: 1) preparation of the planting materials of cereal grains, 2) soil fertility identification techniques, 3) farming methods, 4) use of fertilizers, 5) land preparation and culture management, 6) planting methods, 7) pests, insects, and disease management, and 8) harvesting and storing. They also bothered with environmental issues and problems.
\end{abstract}

Index Terms - Ethnofarming, magical, traditional, factual, environmental issues.

\section{INTRODUCTION}

Science as a formal body of knowledge regarding nature has gradually developed through human history. New technologies and scientific discoveries are upon modern man, rendering obsolete at a very rapid pace existing technology [1]. In the maelstrom of all these prodigious changes, some groups of people have not felt the impact of modern science on their lives [2]. They have retained their own native way of describing and interpreting nature, their indigenous beliefs and practices in farming, medicine, and food gathering techniques. Ethnofarming practices of Subanen and Mansaka falls under the level of ethnoscience. Thus, ethnoscience is ethnic or "native science", the indigenous scientific practices or the "science" that is practiced by ethnic or indigenous groups [2]. Indigenous groups in Mindanao often use celestial bodies or the stars as their basis or guide for their farming, hunting, fishing and other livelihood activities, beliefs, practices and traditions [3]. They believe that "pamitoon" is unique among them as the foundation of their way of living. Tawi-Tawi's astronomical lore is very common among Badjaos. With the awareness of this lore encoded in the racial memory they will not only be enjoying the sky when looking at it at night, they will be also be reading -- and will be reminded of -- their own past and culture [1].

Similarly, Igorot cosmology is generally considered part of the group's folk tales; however, organic farmers claim that this traditional cosmology has some scientific basis. Greg Kitma of Baguio City, who considers himself a biodynamic organic farmer, says that the level of gravitational pull of the moon varies during its different phases. The earth's

Manuscript received September 28, 2013; revised November 29, 2013.

Anabelie V. Valdez is with the Mindanao State University, Philippines (e-mail: anabelievillavaldez@gmail.com). gravitational pull also reacts in certain ways during the different phases of the moon or during certain planetary or star alignments. These gravitational processes affect how plants grow in the same way that there is high or low tide during certain lunar phases. He follows a cropping calendar based not only on the phases of the moon but also on other movements of the solar system. He said that it would be good to plant root crops such as potatoes and yam during certain phases of the moon when its gravitational pull is weaker than that of the Earth. Crops such as beans, tomatoes and eggplant are best planted during a full moon, when the gravitational pull of the moon is stronger. Crops planted or seeds sown when the moon is beginning to reappear after lened (new moon) will grow as the moon's phase turn into a full moon. Therefore, planting after full moon when it fades out into a new moon is avoided [4].

Examination and exploration of the ethnoscientific practices of Subanen and Mansaka are the main objectives of this undertaking. A study of the indigenous practices and ethnoscience of indigenous peoples in the Philippines, specifically the Subanen and Mansaka is potentially beneficial to them. The results and findings of the study could provoke thoughtful reflection on their past and contribute to their knowledge trove. Furthermore, the government, especially the education department, private organizations and other groups of people, may also profit from the findings of the study.

\section{Methodology}

\section{A. Research Design and Methods}

This research utilized the qualitative survey research design using ethnographic techniques to capture the perspectives of the indigenous peoples accurately to understand the ethnoscience of two selected indigenous groups in Mindanao particularly their ethnofarming practices. Each group was studied for duration of two (2) months of intensive field works and immersion and taking field notes.

Purposive and snowball sampling were used to select the participants of this qualitative and naturalistic study. Instruments used were questionnaire interview guide, observation checklist, field notebook, video camera and digital recorder. The processes of collecting data were flexible that is, emerging from the circumstances encountered in the field, and typically involved a contextual response to the lived realities that arouse unpredictably in the course of the field works during focus group discussions, individual interviews, observations, and immersion in the community. Data were analyzed qualitatively through themes [5], [10].

\section{B. Participant of the Study}

The key informants for each of the Subanen and Mansaka 
community were selected based on any one of the following inclusion criteria:

1) A tribal leader or elder in each tribe. Tribal leaders or elders were preferred because they are more knowledgeable about the indigenous practices of their tribe since they retain most of the indigenous knowledge in the tribe; in other words they could be considered "authorities" in their own right. Each one is also a head of the community at the same level as the barangay captain.

2) Farmers that are not less than 45 years old and highly recommended by the gatekeepers (municipal mayor, barangay captain) and tribal leaders. They were the best sources of information or data that I used to answer my research questions.

3) Farmers, regardless of age, who are willing to share their experiences in farming.

\section{RESULTS AND DISCUSSIONS}

\section{A. Ethnoagriculture}

The primary crops planted by Subanen and Mansaka farmers are rice and corn which are their major staple food.

Indigenous farming practices of Subanen and Mansaka that are coded under the factual theme due to its factual justification based on the published scientific standard includes [7]; a) selection and preparation of planting materials such as the physical appearance of seeds (without blemish or discoloration); b) determining soil requirements for their crops that is, soil fertility, usually indicated by the color (the darker the richer) and the presence of earthworms' wastes; c) farming method which is monocropping, multiple cropping and crop rotation; d) use and application of fertilizers to their crops. See Fig. 1 and Fig. 2

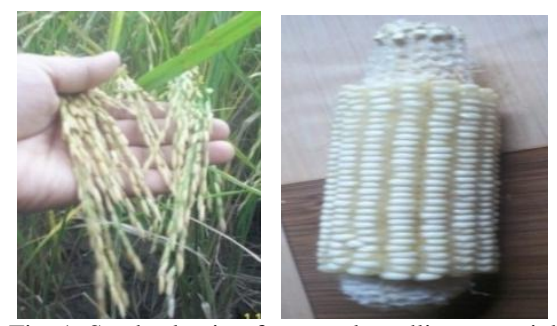

Fig. 1. Seed selection for cereal seedling materials.

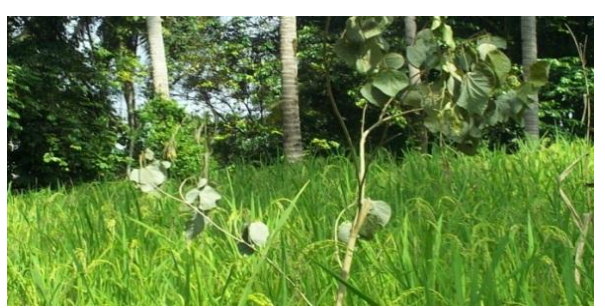

Fig. 2. Tutula tree branch placed at the middle and every corner in the rice field to prevent against insects.

The Subanen and Mansaka's beliefs and practices regarding land preparation and culture management are found to be an amalgam or combination of magical, traditional and factual procedures. The magical and traditional techniques include lihi accompanied by encantations or uttering of magical words or prayers to the unseen spirits. Factual procedure is the kaingin system and weeding [7], [8].

The Subanen and Mansaka traditional practices and beliefs regarding their crops planting method, as revealed, are fusion or combination of the magical, traditional and factual procedures. The magical techniques consist of uttering or reciting of magical words, and prayers to the unseen spirits. The words uttered remain part of undisclosed sacred knowledge. The traditional techniques take the form of lihi, and the perfect time of planting. There are terms or seasons of the year like full moon and high tide that are thought most propitious for planting. The traditional practices of Subanen and Mansaka farmers that show factual justification are the number of seeds to be planted and the spacing method in planting.

The Subanen and Mansaka farmers' traditional beliefs and practices for pest, insect and disease management to protect their crops are found to combine or fuse magical, traditional and factual procedures. The magical techniques are the use of magical words and prayers. The traditional techniques are the use of ginamos, tutula branch, lihi, touring of farm by a breech birth person, and the segregation of crops intended for unseen spirits as a kind of votive offering. The factual techniques are the use of extracted chemicals from plants and the smoking of the farm using plant leaves [6]. See Fig. 3.

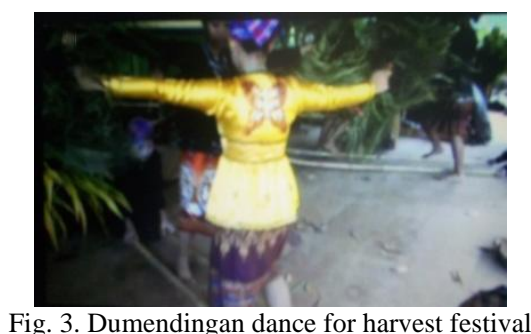

The Subanen and Mansaka farmers' traditional beliefs and practices for harvesting and storing their yield crops are found to be a combination or fusion of magical, traditional, and factual procedure and techniques. The magical technique is in the form of uttering of prayers to the unseen spirits. The traditional techniques consist of the ritual offerings, lihi, and harvest festival. The factual techniques are the perfect time to harvest, the procedure or steps followed in harvest and the storage techniques [5].

Subanen and Mansaka farmers share the same desire or wish to improve or upgrade their knowledge/skills in farming through trainings or workshops about farming for them to have good crop production. They also wish for support from the government.

\section{B. Environmental Issues Affecting Subanen and Mansaka Farmers}

The environmental issues affecting Subanen and Mansaka farmers locally include kaingin. There is also the thinning or denudation of the forest due to encroachment of loggers and developers which has disturbed the habitats of wild flora and fauna. As a result the hunt for animal and plant species is no longer as productive as before.

Mansaka farmers were also affected with soil depletion (fertility/nutrients), erosion, pollution, and lanslides due to legal and illegal mining in their area and deforestation. Compostela Valley is the site of frenetic mining operations which, while a profitable source of livelihood, are fast laying 
waste the land. Natural resources are conserved for biological, economic, and recreational values, natural beauty and importance to local cultures [10]. However, human-induced changes such as kaingin, mining, and grazing land for cattle have led to altered climate patterns. In turn, altered climate patterns have changed the way animals and plants are distributed in different ecosystems ${ }^{[5]}$.

\section{IMPLICATIONS}

The ethnoscientific practices and beliefs of Subanen and Mansaka that have scientific basis based on published scientific standard implies that they are knowledgeable regardless of their low level education and so far have managed and survived with these beliefs and practices. This however, begs the questions: Are they better off, given the circumstances in which they live and the state or level of their ethnoscience? Would it not profit those more to learn, through education, more advanced ways of applying their indigenous knowledge?

Their belief in the existence and power of unseen spirits whose beneficence, compassion and permission they beseech through rituals and prayers manifests their closeness to, and reverence for the sacredness of creation. Perhaps, there is more than knowledge that their modern and educated countrymen could learn from these people.

The Subanen and Mansaka people themselves realize the need for training to enhance their indigenous knowledge and hone their skills. Implicit in their wish is an acknowledgement of their limitations and inadequacies, and their willingness and determination to rise above these.

\section{REFERENCES}

[1] M. Tan. (2008). Mamahi: Stars of Taw-tawi. Philippine Daily Inquirer. Retrieved August 11, 2009. [Online]. Available: http://opinion.inquirer.net
[2] P. R. Brass, "Ethnicity and nationalism," Theory and Comparison, New Delhi, London. SAGE Publication, 1991.

[3] F. C. Polenda, A Voice from the Hill Essays on the Culture, World View of the Western Bukidnon Manobo People, Manila, Linguistic Society of the Philippines, 1989.

[4] M. Malanes. (2008). Heavenly Bodies. "camote" and Igorot weddings. Philippine Daily Inquirer, Northern Luzon. [Online]. Available: http://opinion.inquirer.net.

[5] M. Hennick et al., Qualitative Research Methods, SAGE Publication Ltd., Olivers Yard 55 City Road London, 2011.

[6] A. L. Abellanosa and H. M. Pava, Introduction to Crop Science, Publication office, CMU Bukidonon, Philippines, 1987.

[7] P. Barlett, "Adaptive Strategies in peasant agricultural production," Annual Review of Anthropology, Princeton University Press, 1980.

[8] P. Barlett, "Adaptive strategies in peasant agricultural production," Annual Review of Anthropology, Princeton University Press, vol. 9, pp. 545-573, 1980.

[9] J. W. Creswell, "Research design," Qualitative and Quantitative Approaches, Thousand Oaks, California. SAGE Publications, Inc., 1994.

[10] B. Orlove et al. (2009). Indigenous climate knowledge in southern Uganda. The Multiple Components of a Dynamic Regional System. [Online]. Available: http://www.jstor.org/pss/258229

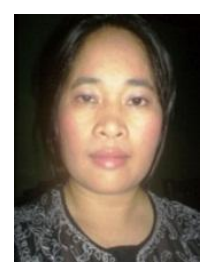

Anabelie V. Valdez was born at Aurora Zamboanga de Sur Philippines on March 16, 1975. She finished Ph.D. science education biology, Ph.D. educational management, master's in secondary teaching general science and bachelor of Science secondary education biology in Mindanao State University Marawi City Philippines. She is the chairman in the academic committee at MSU-Balindong Community High School, a regular lecturer in the MSU SASE reviews, and lecturer in private review center for the licensure examination for teachers. She wrote 6 researcher related to educational innovations and one research about ethnoscience of indigenous people in Mindanao. Dr. Valdez is a member of the DOST-SEI scholar society and a licensed secondary biology teacher. She presented some papers in the international conference held in the Philippines namely; "World Research Festival", and the $5^{\text {th }}$ SSEASR on healing, religion and beliefs. Recently, she presented her paper in the 2013 IEDRC held at Jakarta Indonesia last July 13-14, 2013. 